\title{
The sensitivity of fluvial flood risk in Irish catchments to the range of IPCC AR4 climate change scenarios
}

\author{
Satish Bastola*, Conor Murphy, John Sweeney \\ Irish Climate Analysis and Research UnitS (ICARUS), Department of Geography, National University of Ireland, Maynooth (NUIM), Ireland
}

\section{A R T I C L E I N F O}

\section{Article history:}

Received 19 May 2011

Received in revised form 19 August 2011

Accepted 23 August 2011

Available online 23 September 2011

\section{Keywords:}

Sensitivity analysis

Weather generator

Flood frequency

Hydrological impact

GLUE

Ireland

\begin{abstract}
A B S T R A C T
In the face of increased flood risk responsible authorities have set out safety margins to incorporate climate change impacts in building robust flood infrastructure. Using the case study of four catchments in Ireland, this study subjects such design allowances to a sensitivity analysis of the uncertainty inherent in estimates of future flood risk. Uncertainty in flood quantiles is quantified using regionalised climate scenarios derived from a large number of GCMs (17), forced with three SRES emissions scenarios. In terms of hydrological response uncertainty within and between hydrological models is assessed using the GLUE framework. Regionalisation is achieved using a change factor method to infer changes in the parameters of a weather generator using monthly output from the GCMs, while flood frequency analysis is conducted using the method of probability weighted moments to fit the Generalised Extreme Value distribution to 20,000 annual maximia series. Sensitivity results show that for low frequency events, the risk of exceedence of design allowances is greater than for more frequent events, with considerable implications for critical infrastructure. Peak flows for the five return periods assessed were found to be less sensitive to temperature and subsequently to potential evaporation (PET) than to rainfall. The average width of the uncertainty range for changes in flood magnitude is greater for low frequency events than for high frequency events. In all catchments there is a progressive increase in the peak flows associated with the 5, 25, 50 and 100-year return periods when moving from the 2020s to the 2080s.
\end{abstract}

(c) 2011 Elsevier B.V. All rights reserved.

\section{Introduction}

Projected changes in climate are expected to increase flood risk in north western Europe (e.g., Lehner et al., 2006; Wilby et al., 2008; Murphy and Charlton, 2008). In responding to such risks, responsible authorities have set out design allowances to incorporate climate change impacts in building robust flood infrastructure. Such safety margin strategies aim to reduce vulnerability at null or low costs. When it is cheap, particularly at design stage, Hallegatte (2009) highlights that it is prudent to add security margins to design criteria to improve the resilience of infrastructure to future (expected or unexpected) shocks. This paper sets out to subject such design allowances to a sensitivity analysis of the uncertainty inherent in estimates of future flood risk. We use Ireland as a case study where policy guidance such as the Greater Dublin Strategic Drainage Study (GDSDS) sets out that all new development must allow for a $20 \%$ increase in peak flows for all return periods up to 100 years to allow for climate change. Similarly, the Office of Public Works (OPW), the national body responsible for flood risk management in Ireland has advised an allowance of $+20 \%$ of peak flows under a mid-range future scenario and $+30 \%$ as a high-end scenario (OPW, 2009). Such decisions are crucial to

\footnotetext{
* Corresponding author. Tel.: + 35317086592.

E-mail address: Satish.bastola@nuim.ie (S. Bastola).
}

the protection of lives, livelihoods and critical infrastructure and therefore need to be subjected to sensitivity analysis to demonstrate how robust such safety margin approaches are to uncertainty in future impacts (Prudhomme et al., 2010).

In the past two decades a large body of work has dealt with the application of hydrologic models for assessing the potential impacts of climate change on a variety of water resource issues. Such assessments have predominantly been based on what Wilby and Dessai (2010) term a 'top-down' approach involving the propagation of future climate scenarios through hydrological models (predominantly a single hydrological model) (e.g., Arnell and Reynard, 1996; Xu, 1999; Bastola et al., 2011), to derive an estimate of a future impact metric which is subsequently provided for policy makers to decide on appropriate adaptation options. Despite their widespread application, such approaches have met with limited success (Wilby and Dessai, 2010), in large degree due to the uncertainty in future simulations of relevant impacts.

Within this framework, Global Climate Models (GCMs) have emerged as the dominant tool in producing future climate scenarios through modelling natural processes as closely as possible. However, there are considerable uncertainties associated with the use of GCMs (see Prudhomme et al., 2003), while others (e.g. Kay et al., 2006; Rowell, 2006; Bastola et al., 2011) have shown that GCM uncertainty is by far the largest contributor to the cascade of uncertainty associated with future impacts. Such uncertainties mean that where decisions 
are made it is imperative that a range of GCMs is included, so that a fuller understanding of the uncertainty space can be developed. Therefore, recent studies have moved towards employing a diverse range of GCMs driven by a number of plausible emission scenarios to generate quantitative measures of uncertainty (e.g., Taye et al., 2010; Bae et al., 2011). In recognition of the considerable uncertainties associated with climate change impact projections the focus of modelling has moved towards decision appraisal rather than top down, predict and provide approaches that have been the mainstay of traditional impact assessment (Prudhomme et al., 2010; Wilby and Dessai, 2010).

Due to the cascade of uncertainty associated with scenario led approaches, the range of impacts and their implied adaptation responses can become impracticable (Wilby and Dessai, 2010). Therefore, the utility of probabilistic based approaches in adapting a risk-based framework for impact assessment has been increasingly advocated by recent studies (e.g., Räisänen and Palmer, 2001; Giorgi and Mearns, 2003). Scenario-led approaches which include only a few scenarios and GCMs are not compatible with the notion of a probabilistic, risk based framework. Furthermore, continuous research in the field of climate change and impact studies is likely to continuously result in new scenarios with new emerging knowledge that adds to the uncertainty cascade. Therefore, the inclusion of new scenarios and GCMs in the analysis, though desirable, will require analyses to be redone with additional scenarios for formulating robust decision making. Consequently, the idea of using the output from a number of GCMs for sensitivity testing and adaptation options appraisal has surfaced more recently as a more cautious approach (e.g. Prudhomme et al., 2010; Hall and Murphy, 2010; Lopez et al., 2009).

In understanding local scale impacts the direct application of GCMs is difficult given their coarse spatial resolution, which typically requires some form of downscaling. Regional climate models (RCMs) use a dynamic, physically based approach to downscale the larger resolution GCM variables to a higher resolution (typically $50 \mathrm{~km}$ ) over a limited area. Such techniques are computationally expensive as they explicitly describe the physical properties affecting climate. Additionally, the output from regional climate models often require further downscaling if they are to be applied for hydrological simulation at the catchment scale. With the inclusion of more GCMs the computational cost required to better characterise the outputs from these models is immense. A computationally cheap alternative for downscaling is the statistical approach where empirical relationships are typically established between GCM-resolution climate variables and local climate. Such techniques offer the possibility of including a larger number of GCMs in the analysis. Climate change scenarios generated from statistical downscaling (e.g., using a stochastic weather generator) offer a significant computational advantage over dynamical downscaling methods in sensitivity testing and adaptation options appraisal where the focus is on populating the uncertainty space, with less emphasis placed on the precision of single scenarios.

In facilitating the inclusion of output from a large number of GCMs one of the simplest of the statistical methods is the perturbation method (e.g., Prudhomme et al., 2002). In this method, the change factor derived from the control and future GCM simulation is used to adjust the observations in an additive way for temperature and in a multiplicative way for precipitation. Alternatively, the GCM-derived changes have also been used to infer changes in the parameters of a weather generator, which are then used to simulate rainfall timeseries under current and future climates for use as input to continuous hydrological models (Schreider et al., 2000; Tung, 2001; Fatichi et al., 2011).

In moving this area of work forward, Prudhomme et al. (2010) presented a framework for a scenario neutral approach in testing the effectiveness of UK government safety margins for flood protection under a wide range of climate change scenarios. In their method, instead of using time varying outcomes for individual scenarios, the sensitivity analysis relied upon plausible ranges of climate changes making it neutral to the scenario used. The key advantage of such an approach as outlined by the authors is that the sensitivity domain can cover the entire spectrum of the latest IPCC-AR4 GCMs outputs, while it can also be adjusted to include additional values at both ends of the spectrum to plan for surprise and potential new extreme projections by adjusting the sensitivity domain. Such an approach is compatible with a probabilistic framework by combining knowledge of hazard likelihood with the sensitivity of a catchment (discussed further in Prudhomme et al., 2010).

A potential approach for conducting a sensitivity analysis is to use a full factorial experimental design, in which the model is solved for all possible combinations of the parameters. While this is desired, if there are a large number of parameters to analyse, the number of model solutions which must be obtained can be a limiting factor. In overcoming this, the dimensionality of the sensitivity matrix can be reduced by reducing the number of parameters. For example, Prudhomme et al. (2010) synthesised the monthly change factors from a large number of GCMs using a three parameter harmonic function. Sensitivity analysis shows the effect of varying these parameters over the range of uncertainty that the decision maker has about the exact values of those parameters. Such analysis demonstrates how robust the decision recommended by the models is to the imprecision of knowledge about the uncertainty domain.

The aim of this paper is to analyse the sensitivity of fluvial flood risk to the uncertainty in climate change by incorporating different sources of uncertainty and utilising key features of an ensemble of climate models. In addition to uncertainties in emission scenario and climate model selection, uncertainties arising from hydrological model structure and parameters are also incorporated for four case study catchments. In doing so the safely margin allowances for food infrastructure suggested in Irish policy guidance will be stress tested. Such an analysis will question the allowances made for climate change in critical infrastructure, enable more robust adaptation decisions and exemplify a case study for the analysis of adaptation decisions. The remainder of the paper is structured as follows; first the general steps of the methodology are laid out and information is provided on the study catchments and future changes in temperature and rainfall likely for the study region. Section 2.2 details the generation of climate data using the change factor approach coupled with a stochastic weather generator. Section 2.3 outlines the hydrological models used and their application, while Section 2.4 details the application of the flood frequency analysis. The inclusion of natural variability is discussed in Section 2.5. Finally, the uncertainty of future changes in flood peaks associated with current return intervals and the sensitivity testing of design allowances are demonstrated for the case study catchments.

\section{Material and methods}

The methodology used to assess the impact of climate change on the frequency of extreme events and their sensitivity to future change is based on the idea of a scenario neutral approach proposed by Prudhomme et al. (2010). Here, however, the change factor approach is used to inform the parameters of a weather generator to produce continuous time series of change and the uncertainty space includes the uncertainty from rainfall runoff models and their parameters. While hydrological model uncertainty is not as large as that from GCMs it has been shown to be a significant contribution to the total uncertainty envelope (Bastola et al., 2011) and also interacts differently with the same scenario input. The steps adopted in this study are as follows (also shown schematically in Fig. 1):

(1) Select a wide range of GCMs developed by various climate centres and a number of plausible emission scenarios that provide output on the future climate for the selected region. In this study we use the IPCC AR4 scenarios ( 17 GCMs $\times 3$ SRES emission scenarios). 


\section{Annual Rainfall (mm)}

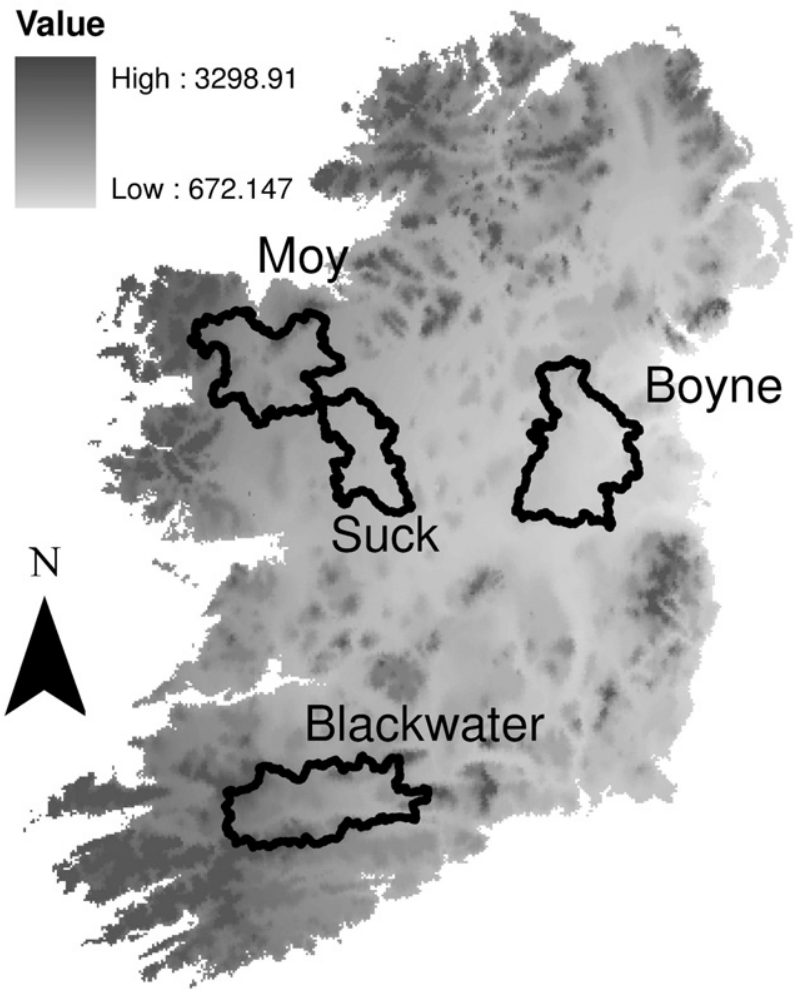

Fig. 1. Location and boundaries of the case study catchments.

(2) Derive the monthly change factors from the control and future GCM simulations.

(3) Model the monthly change factors using a simple cosine curve to reduce the dimensionality of sensitivity analysis.

(4) Select the range of parameters of the cosine curve from the ensemble of the modelled cosine curves that represent the monthly change factors.

(5) Force hydrological models with climate scenarios generated using all possible combinations of parameters of the cosine curve i.e., a full factorial experiment of parameters for sensitivity analysis.

(6) From the simulations, derived in step 5, analyse the flood frequency and estimate the flood quantiles for specified return periods.

\subsection{Data and GCM projections}

The area of focus for this study is the Republic of Ireland (Fig. 1) where the impact of climate change on flood frequency at the catchment scale is investigated using four Irish catchments, namely; the river Blackwater at Ballyduff $\left(2302 \mathrm{~km}^{2}\right)$, the river Suck at Bellagill $\left(1219 \mathrm{~km}^{2}\right)$, the Moy at Rahans $\left(1803 \mathrm{~km}^{2}\right)$, and the Boyne at Slane $\left(2452 \mathrm{~km}^{2}\right)$. These four catchments were selected so that they represent the diverse hydrological responses of different catchments located throughout the Republic of Ireland. The catchment characteristics are shown in Table 1. Observed precipitation and temperature data were obtained from Met Éireann, the Irish National Meteorological Service. The river discharge data used to condition the hydrological models was obtained from the Office of Public Works (OPW) at http:// www.opw.ie/hydro/index.asp?mpg=main.asp.

A large number of climate change experiments using GCMs forced with SRES (Special Report on Emission Scenarios) emission scenarios have been completed in recent years. The results of experiments at several modelling centres are currently available from the IPCC DDC (Data Distribution Centre) at http://www.ipcc-data.org. The data period used in this study was 1971-2100 and the climatic variables analysed were monthly mean temperature and precipitation. Table 2 shows the list of the $17 \mathrm{GCMs}$, modelling group, country of origin, spatial resolution and number of cells representing Ireland. Each of these GCMs was run with the A1B, A2 and B1 SRES emission scenarios, all of which were used in this study and comprise 51 future climate scenarios ( $17 \mathrm{GCMs} \times 3$ SRES emission scenarios). As the spatial resolution of the GCMs used varies, re-gridding was done prior to extraction. Due to the difference in spatial resolution of the GCMs used in this study, all GCMs were suitably regridded to conform to the spatial resolution of $3.75 \times 3.75^{\circ}$ prior to extraction. This averaging would approximate the republic of Ireland as a single grid cell. The 20C3M experiment which represents the climate of the 20th century is used as a control run. This experiment runs with greenhouse gases increasing as observed through the 20th century. The analysis is presented for three future periods namely 2011-2040 (referred to as 2020s), 2041-2070 (referred to as 2050s), 2071-2100 (referred to as 2080s).

\subsection{Monthly change factors and the generation of climate scenarios}

A variety of methods are available to estimate climatological variables for future times and at spatial scales that are appropriate for local scale impact assessment. Owing to the simplicity and speed at which it can be applied, the Change Factor Methodology (CFM) is still widely used in impact analysis studies. The first step of the CFM method is to establish a baseline climatology for the area of interest. Secondly, changes in the equivalent variable for the GCM grid box closest to the target site are calculated as

$\Delta P=\left(P^{\prime}-P\right) / P ; \quad \Delta T=\left(T^{\prime}-T\right)$

where $\Delta P$, and $\Delta T$ are the change factors for precipitation and temperature, the primed quantities correspond to the future while unprimed quantities correspond to the baseline period (control period). In the final step the changes estimated are simply added to each day in the baseline time series. The resultant scenario incorporates the station information as well as the change of the specified GCM grid box. The procedure assumes that the spatial pattern of the present climate remains unchanged in the future. The method, however, cannot be used to explore transient changes in local climate scenarios as the $\mathrm{CF}$ derived is specific to the selected time slice.

Table 1

Catchment descriptors.

\begin{tabular}{|c|c|c|c|c|c|c|c|c|c|c|c|}
\hline \multirow[t]{2}{*}{ River and gauge } & \multicolumn{9}{|c|}{ Catchment descriptors } & \multirow{2}{*}{$\begin{array}{l}\text { Average } \\
\text { rainfall } \\
(\mathrm{mm})\end{array}$} & \multirow{2}{*}{$\begin{array}{l}\text { Mean } \\
\text { discharge } \\
\text { (cumecs) }\end{array}$} \\
\hline & Area $\left(\mathrm{km}^{2}\right)$ & S1085 & SAAR $(\mathrm{mm})$ & SAAPE $(\mathrm{mm})$ & Forest $\%$ & Peat $\%$ & Pasture\% & BFI soils & Altbar & & \\
\hline Blackwater at Ballyduff & 2302 & 1.34 & 1200 & 516 & 0.14 & 0.05 & 0.79 & 0.62 & 165.6 & 3.1 & 62.3 \\
\hline Boyne at Slane Castle & 2452 & 0.68 & 890 & 504 & 0.04 & 0.05 & 0.89 & 0.69 & 90.9 & 2.4 & 35.4 \\
\hline Moy at Rahans & 1803 & 0.74 & 1323 & 461 & 0.09 & 0.32 & 0.51 & 0.76 & 81.2 & 3.9 & 57.9 \\
\hline Suck at Bellagill & 1219 & 0.39 & 1046 & 466 & 0.08 & 0.21 & 0.69 & 0.58 & 75.6 & 2.8 & 25.2 \\
\hline
\end{tabular}


Table 2

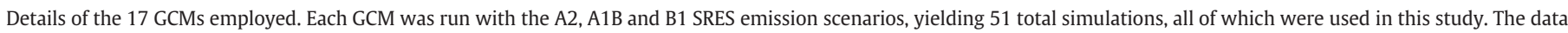
period analysed was 1971-2100 and the climatic variables analysed were monthly mean temperature and precipitation.

\begin{tabular}{|c|c|c|c|c|c|}
\hline Sn & Model (GCM) & CERA (acronym) & Modelling group & Spatial resolution mesh $-($ lon $\times$ lat $)$ & No of cell \\
\hline 1 & BCCR-BCM2.0 & BCM2 & Bjerknes Centre for Climate Research (Norway) & Gaussian $-128 \times 64$ & 2 \\
\hline 2 & CCSM3 & NCCCSM & National Centre for Atmospheric Research (USA) & Gaussian $-256 \times 128$ & 9 \\
\hline 3 & CGCM3.1 (T47) & CGMR & $\begin{array}{l}\text { Canadian Centre for Climate Modelling and Analysis (Canada) } \\
\text { Météo-France/Centre National de Recherches Météorologiques }\end{array}$ & Gaussian $-96 \times 48$ & 1 \\
\hline 4 & CNRM-CM3 & CNCM3 & (France) & Gaussian $-128 \times 64$ & 2 \\
\hline 5 & CSIRO-Mk3.0 & CSMK3 & CSIRO Atmospheric Research (Australia) & Gaussian $-192 \times 96$ & 4 \\
\hline 6 & ECHAMS/MPI-OM & MPEH5 & $\begin{array}{l}\text { Max Planck Institute for Meteorology (Germany) } \\
\text { Meteorological Institute of the University of Bonn/KMA }\end{array}$ & Gaussian $-192 \times 96$ & 4 \\
\hline 7 & ECHO-G & ECHOG & Meteorological inst., and M \& D group (Germany/Korea) & Gaussian $-96 \times 48$ & 1 \\
\hline 8 & GFDL-CM2.0 & GFCM2O & Geophysical Fluid Dynamics Laboratory (USA) & Regular $-144 \times 90$ & 3 \\
\hline 9 & GFDL-CM2.1 & GFCM21 & Geophysical Fluid Dynamics Laboratory (USA) & Regular $-144 \times 90$ & 3 \\
\hline 10 & GISS-ER & GIER & NASA/Goddard Institute for Space Studies (USA) & Regular $-72 \times 46$ & 1 \\
\hline 11 & INM-CM3.0 & INCM3 & Institute for Numerical Mathematics (Russia) & Regular $-72 \times 45$ & 1 \\
\hline 12 & IPSL-CM4 & IPCM4 & $\begin{array}{l}\text { Institute Pierre Simon Laplace (France) } \\
\text { National Institute for Environmental Studies, and Frontier Research }\end{array}$ & Regular $-96 \times 72$ & 2 \\
\hline 13 & MIROC3.2 (medres) & MIMR & Centre for Global Change (Japan) & Gaussian $-128 \times 64$ & 2 \\
\hline 14 & MRI-CGCM2.3.2 & MRCGCM & Meteorological Research Institute (Japan) & Gaussian $-128 \times 64$ & 2 \\
\hline 15 & PCM & NCPCM & National Centre for Atmospheric Research (USA) & Gaussian $-128 \times 64$ & 2 \\
\hline 16 & UKMO-HadCM3 & HADCM3 & UK Met. Office (UK) & Regular $-96 \times 73$ & 2 \\
\hline 17 & UKMO-HadGEM1 & HADGEM & UK Met. Office (UK) & Regular $-192 \times 145$ & 6 \\
\hline
\end{tabular}

A number of studies have observed that the CF calculated from a specified period is sensitive to the period selected (e.g., Kendon et al., 2008; Prudhomme et al., 2010). Therefore, the effect of sampling uncertainty on the estimated $\mathrm{CF}$ is addressed using a block sampling method where a continuous 20-year data block is sampled from the 30 year series of data representing control and future periods. Subsequently, the ensemble of change factors is estimated from each sample of monthly precipitation and temperature for all the selected GCM projections and emission scenarios. A change factor corresponding to median value of each of the 51 climate scenarios is selected and employed hereafter.

From the range of change factors, regional sequences of precipitation and temperature are derived by suitably modifying the parameters of a weather generator based on the monthly CFs for precipitation and the annual change factors for maximum and minimum temperature. For precipitation this requires sampling 12 parameters, each representing a change factor for each month. Therefore, following Prudhomme et al. (2010) a harmonic analysis was applied to model the monthly CFs and to synthesise and smooth the larger inter-annual variations, reducing the required number of parameters to three (Eq. (2)).

$\mu_{t}=\bar{\mu}+A \cos \left(\frac{2 \pi}{P} t-\phi\right)$

where $\mu_{t}$ is the value of the series at time $t, \bar{\mu}$ is the arithmetic mean, $A$ and $\Phi$ are the amplitude and phases (in radian), $P$ is the period of observation. The phase angle $\Phi$ indicates the time of year the maximum of a given harmonic occurs and was converted to months (Kirkyla and Hameed, 1989).

The weather generator employed is WGEN (Richarsdon and Wright, 1984). Wilks (1992) provide a method to adapt the calibrated parameters of WGEN to changing climate. In this study, 100 sets of different precipitation and temperature scenarios were constructed. For the generation of the future climate scenarios, the parameters calibrated for Irish synoptic weather stations were adapted accordingly from Bastola et al. (2011) and Wilks (1992). Bastola et al. (2011) provide a full evaluation of the application of WGEN to Irish conditions. In addition to comparing observations Bastola et al. (2011) also compared WGEN generated future climate scenarios against available regional climate scenarios developed for Ireland using alternative techniques. Therefore only a brief description of the application of WGEN is provided here. In this method, the monthly change in mean and variance of the selected variables between the simulated control and future are utilised (Eqs. (3) and (4)).

$\mu^{\prime} / \mu=\pi^{\prime} \alpha^{\prime} \beta^{\prime} / \pi \alpha \beta \quad$ where $\pi=p_{01} /\left(1+p_{01}-p_{11}\right)$

$\left(\sigma / \sigma^{\prime}\right)^{2}=\frac{\pi^{\prime} \alpha^{\prime} \beta^{\prime 2}\left[1+\alpha^{\prime}\left(1-\pi^{\prime}\right)\left(1+d^{\prime}\right) /\left(1-d^{\prime}\right)\right]}{\pi \alpha \beta^{2}\left[1+\alpha^{\prime}\left(1-\pi^{\prime}\right)\left(1+d^{\prime}\right) /\left(1-d^{\prime}\right)\right]}$ where $d=p_{01}-p_{11}$

where the primed quantities corresponds to the future and are unknown, $p_{01}$ and $p_{11}$ represent the probability of a wet day following a dry day and a wet day following a wet day, $\mu$ and $\sigma$ are the seasonal mean and variance of precipitation. WGEN has four parameters that need to be adjusted to changing climate i.e. four constraints are required. The constraints, defined by Eq. (5), are used to adjust the parameters of WGEN in simulating future climate.

$$
\begin{aligned}
\mu^{\prime} / \mu & =C F ; \sigma^{\prime 2} / \sigma^{2}=\left(\mu^{\prime} / \mu\right)^{1.31} ; \pi_{i}^{\prime} / \pi_{i}=a\left(\mu^{\prime} / \mu\right) ; d_{i}^{\prime} / d_{i}=1 ; i \\
& =1,12 \text { (month) }
\end{aligned}
$$

Again, the primed quantities correspond to the future and are unknown, coefficient $a$ (is the slope coefficient representing season). The modification of the parameters related to both the occurrence and magnitude of precipitation are derived from GCMs e.g., changes in wet days probability, monthly wet days precipitation. For the two parameters that are related to the generation of temperature, both are modified based on the change in annual average temperature and the change in the coefficient of variation of temperature derived from GCM outputs.

Potential evapotranspiration (PET) data was estimated using a generalised form of the Hargreaves method (Xu and Singh, 2000); a radiation based empirical model popularly used for the simulation of PET. The empirical method utilises solar radiation, minimum and maximum temperature to compute PET. The solar radiation was estimated from maximum and minimum temperature, extra-terrestrial radiation and coefficients (Hargreaves et al., 1985). The coefficients for estimating solar radiation from temperature for Ireland were taken from Supit (1994).

\subsection{Hydrological modelling}

Uncertainty in the application of rainfall runoff models stems from a variety of sources including; data, parameter, model structure and 
state uncertainty. Despite their acknowledged limitations, conceptual rainfall runoff models continue to be widely used for assessing the impacts of climate change on water resources and for projecting potential ranges of future impacts. Their popularity is related to their availability, low data requirements and computational demands. The uncertainties associated with hydrological models have traditionally been given less attention in impact assessments in comparison to other sources. Therefore in this study the uncertainty in hydrological model structure, along with parameter uncertainty is incorporated into the uncertainty space by using a number of plausible conceptual model structures and their behavioural parameters to transform future climate scenarios into future hydrological series.

From among the large number of models used for the purpose of modelling flow in catchments, we selected four conceptual rainfall runoff models; HyMOD (see Wagener et al., 2001), NAM (see Madsen, 2000), TANK (Sugawara, 1995) and TOPMODEL (Beven et al., 1995). Each model varies in their conceptualisation of key hydrological processes and complexity, primarily related to the number of parameters requiring calibration. NAM and TANK describe the behaviour of each component of the hydrological cycle at the catchment level by using a group of conceptual elements while both TOPMODEL and HyMOD are variable contributing area models. In TOPMODEL spatial variability is accounted for through topographic indices whereas in HyMOD spatial variability is modelled using a probability distribution function. All four models employ a single linear reservoir to model groundwater. Each has been applied in numerous applications and their potential for simulating flow due to climate change has been discussed extensively in the past. The models employed are independently developed by different researchers and organisations.
In order to examine hydrological model uncertainty (parameter and structural uncertainty) a multi-model approach based on Generalised Likelihood Uncertainty Estimation (GLUE) framework is used. The GLUE method introduced by Beven and Binley (1992) has been extensively used (e.g. Freer et al., 1996) and is based on the premise that for a physically based hydrological model, no single optimum parameter set exists; rather a range of different sets of model parameter values may represent the process equally well. Different model structures, as well as different parameter sets in a particular model structure, can be easily combined within this framework.

The application of the GLUE method requires the definition of a likelihood measure, a measure that differentiates behavioural and non behavioural simulators (behavioural threshold) and a measure that sets the relative weights of the behavioural and non behavioural simulators. The behavioural set of model parameters for each of the models and catchments used in this study were taken from Bastola et al. (under review) where the authors used the period of observations from 1971 to 1990 for model calibration and from 1991 to 2000 for model validation. A common assumption implicit in most climate change impact studies is that hydrological models calibrated over the historical period are valid for use in the future under a changed climatic regime. As the calibration period selected by Bastola et al. (under review) is sufficiently long to cover both wet and dry periods, i.e. the 1970 s is a relatively dry decade whereas the 1980 s is relatively wet; and the change in annual precipitation change compared to data that are used during model calibration is within 10\%; the authors assumed that the calibrated parameters are valid for future simulation.

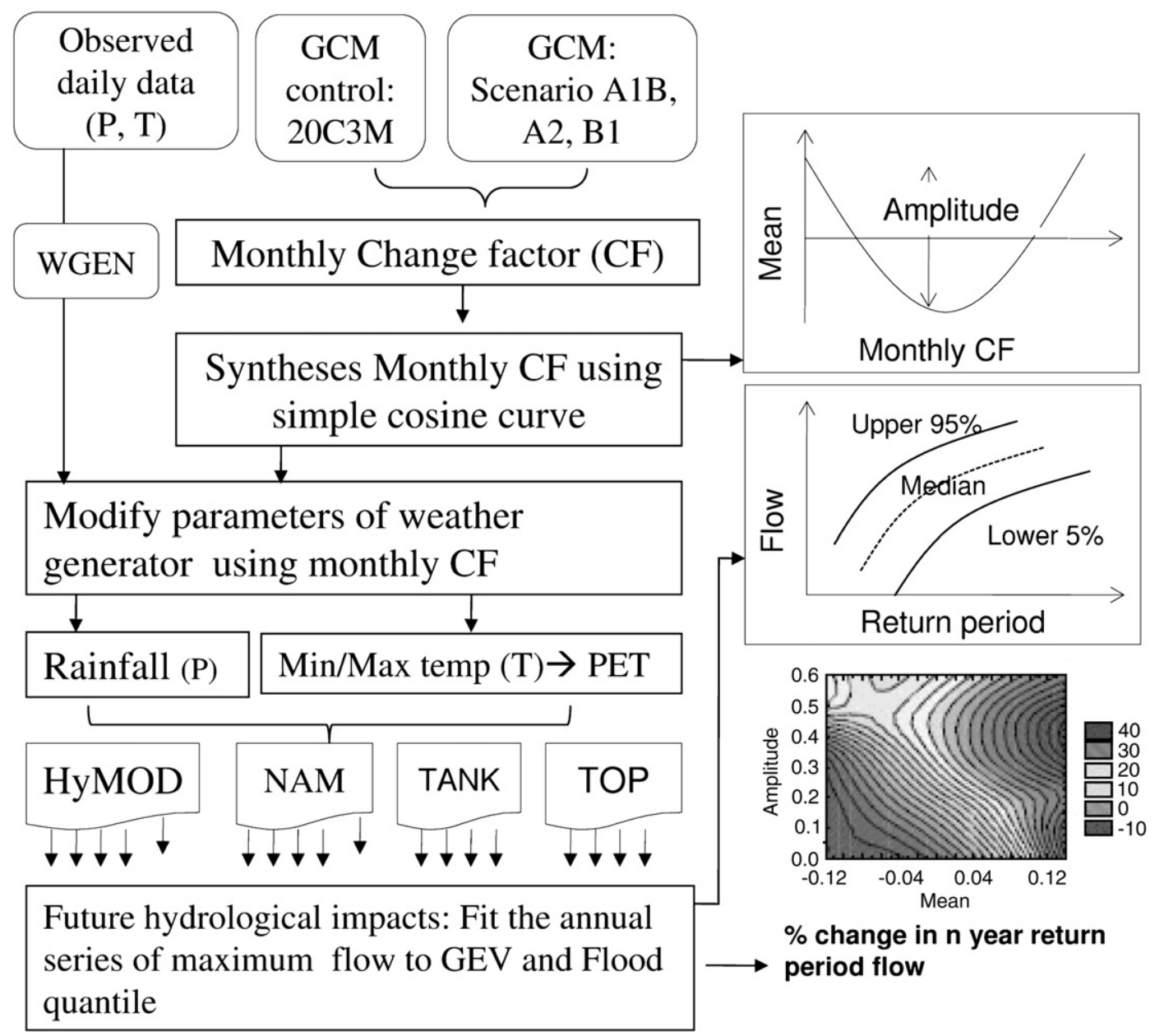

Fig. 2. Schematic outline of the methods used in this study; WGEN is the weather generator, GEV is the Generalised Extreme Value distribution. 
Bastola et al. (2011) used the Nash Sutcliffe Efficiency (NSE) criteria as an informal goodness-of-fit measure which is based on the sum of squared errors. An NSE threshold value of 0.6 was selected and fine tuned for each catchment so that the prediction interval encapsulates as much observation as possible, and maintains a good population of behavioural solutions. Bastola et al. (2011), which used same set of models and catchment, show that prediction interval and their reliability estimated from each of the four models are different among each catchment indicating the important role multimodel simulations can play. Each of the calibrated hydrological models was forced with the generated scenarios.

\subsection{Flood frequency analysis}

The impact of climate change on flood frequency is defined here as the percentage change in the flood peak of a given return period. This definition results in different figures for different return periods and different time slices. A number of researchers have conducted flood frequency analysis using the output from a continuous simulation of river flow (e.g., Cameron et al., 2000; Kay et al., 2006; Cameron, 2006). In such approaches, the analysis of flood frequency involves the selection of a flood frequency model, a statistical distribution and a method for estimating the parameters of the selected distribution. Both the annual maximum series (AMS) and peak over threshold (POT) methods are widely used for frequency analysis (e.g., Madsen et al., 1997). In relation to the statistical distribution for the flood data Ahilan et al. (2011) recommend the Generalised Extreme Value (GEV) distribution for Irish flood data constructed from annual

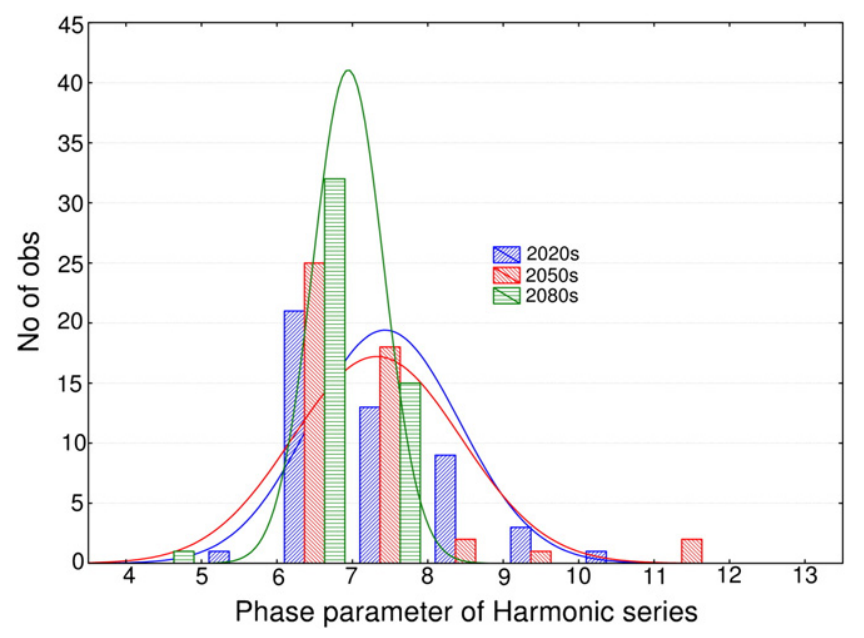

Fig. 4. Distribution of the phase parameter of the harmonic function used for modelling the change factors in precipitation. The distribution is based upon the output from a number of GCMs and scenarios.

maximum series. Therefore we fit the AMS series using the Generalised Extreme Value distribution (GEV) using the method of probabilityweighted moments (Hosking et al., 1985), a method equivalent to L-moments. The method of L-moments has found widespread application in both regional and at-site flood frequency analyses (e.g., Institute of Hydrology, 1999; Kumar and Chatterjee, 2005). To estimate the
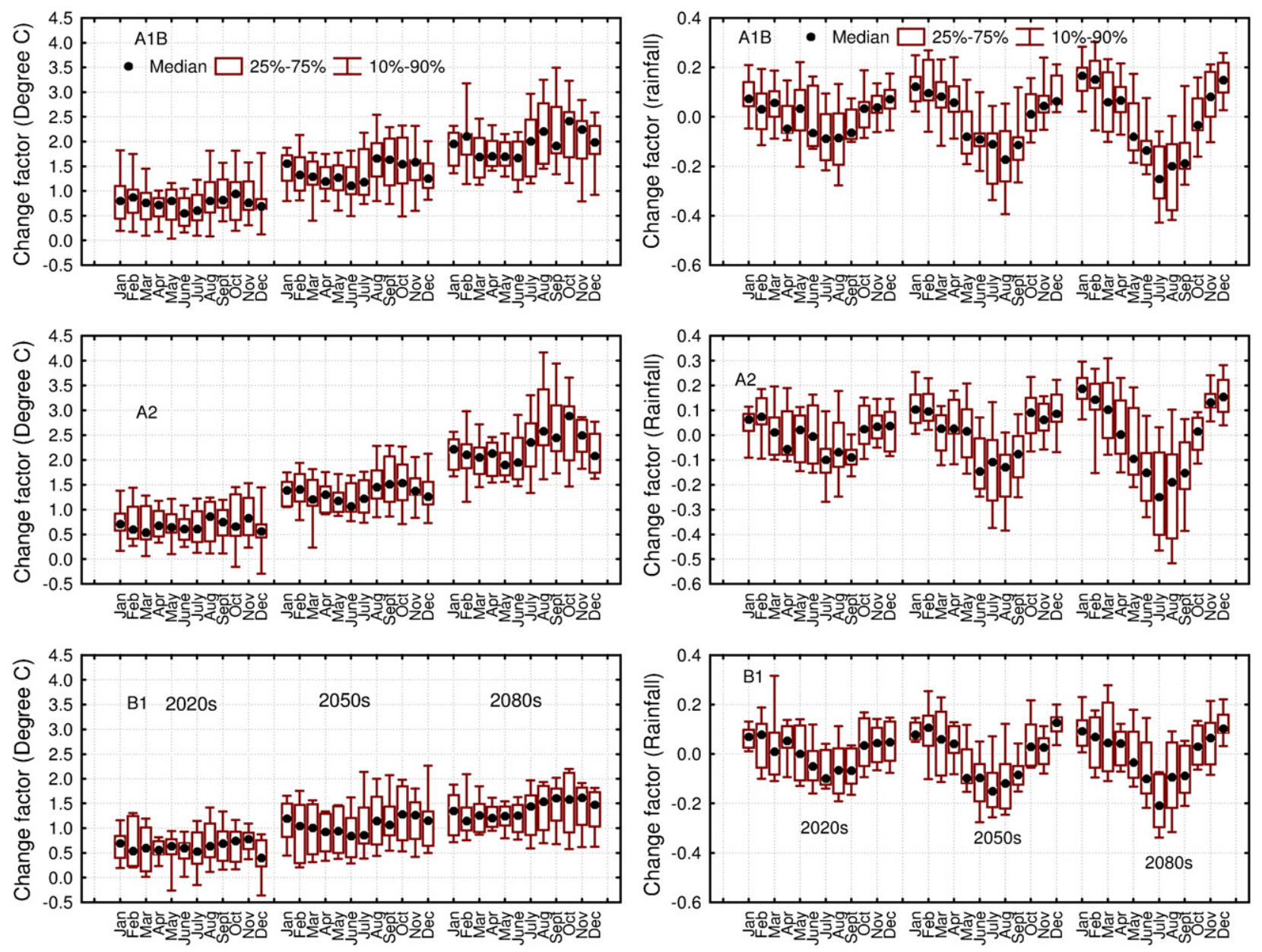

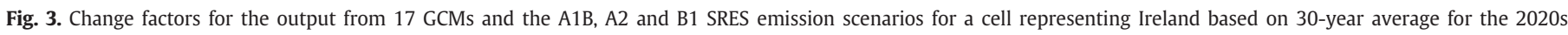
(2011-2040), 2050s (2041-2070) and 2080s (2071-2100) compared to 20C3M control (1961-1990). 


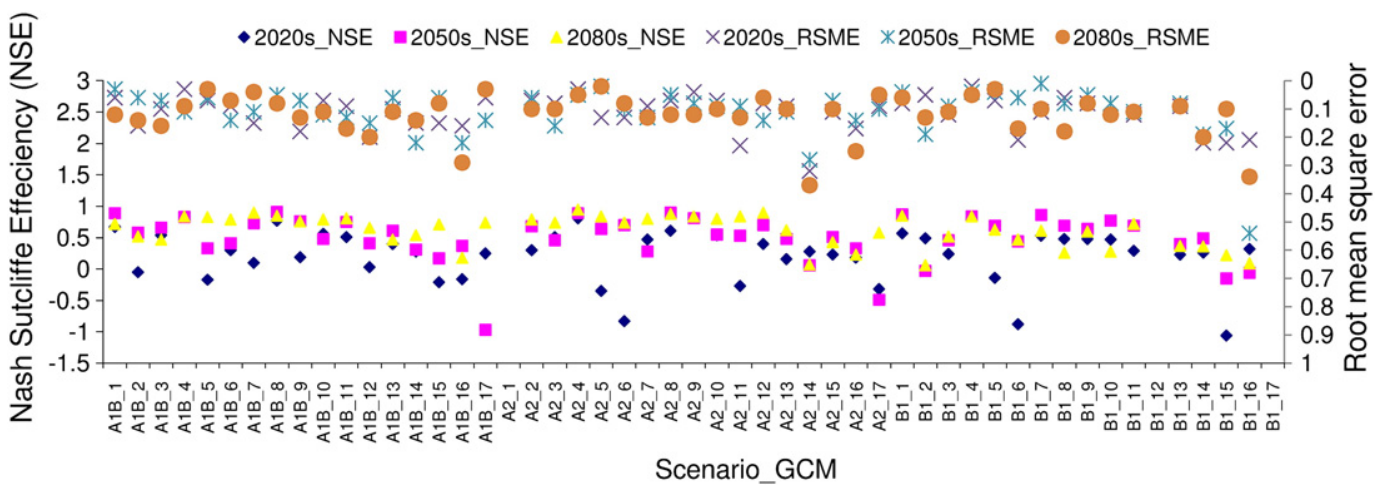

Fig. 5. Nash Sutcliffe Efficiency and root mean square measures of goodness of fit between modelled and GCM estimated monthly change factors for precipitation.

parameters of the GEV distribution in the present study, the relations given by Hosking (1990) for the case of simple L-moments are used. The L moment estimators for the GEV distribution are

$$
\begin{aligned}
& \xi=\lambda_{1}-\frac{\alpha}{\kappa}\{1-\Gamma(1+\kappa)\} ; \alpha=\frac{\lambda_{2} \kappa}{\left(1-2^{-\kappa}\right) \Gamma(1+\kappa)} \\
& \kappa=7.859 c+2.9554 c^{2} ; c=2 /\left(3+\tau_{3}\right)-\log (2) / \log (3) .
\end{aligned}
$$

The L moment estimators $\lambda_{1}, \lambda_{2}, \lambda_{3}$ and $\tau_{3}\left(=\lambda_{3} / \lambda_{2}\right)$ were obtained by using an unbiased estimator of the first three probability weighted moments $\beta_{0}, \beta_{1}$, and $\beta_{2}\left(\lambda_{1}=\beta_{0}, \lambda_{2}=2 \beta_{1}-\beta_{0}, \lambda_{3}=6 \beta_{2}-6 \beta_{1}+\beta_{0}\right)$.

\subsection{Natural climate variability}

Prior to evaluating the impact of change, an estimation of natural variability relative to the climate change signal was undertaken. Re-sampling observed rainfall to produce a large number of resampled rainfall series is a simple approach for simulating natural climate variability. Such an approach however will not take into account the extremes that are absent from the observed record. Therefore, the effect of climate variability is assessed by using WGEN to generate a large number of rainfall time series, representing current climate and extending for 30 years in length (e.g. Cameron, 2006; Kilsby et al., 2007).

\section{Results}

The presentation of results is laid out as follows; Section 3.1 presents results of the change factor analysis, harmonic reduction and the establishment of sensitivity domains for the analysis of uncertainty. Section 3.2 presents the results of the sensitivity analysis of flood peaks to uncertainty in climate change projections, while Section 3.3 examines the range of future impacts projected for selected return periods for each catchment and contextualises them in terms of natural climate variability.

\subsection{Change factors, harmonic reduction and sensitivity domains}

Box and whisker plots in Fig. 3 show the mean and uncertainty in monthly change factors for temperature and rainfall for the A2, A1B, and B1 SRES emission scenarios for the 2020s, 2050s and 2080s. They are all treated with equal weight. The seasonal signal for precipitation is more pronounced than temperature, with the seasonality in precipitation becoming more pronounced with time. Given that the monthly climatological values of precipitation and temperature influence the calculation of change factors and subsequently the generation of climate scenarios, the influence of sampling uncertainty is evaluated by sampling continuous blocks of 20 -year time series from within the control period 1961-2000 and from the three future time slices output from the GCMs. The distribution of seasonal mean precipitation derived from 20 year continuous blocks for each of the three scenarios and future time periods revealed (not shown) that the effect of sampling uncertainty on monthly climatological values is minimal. Therefore, a median value for seasonal mean precipitation and an estimation of the range of values derived from the selected GCMs are used for estimating the change factor in seasonal mean precipitation.

The change factors for precipitation were then modelled using a simple three parameter cosine curve (Eq. (2)) to synthesise and smoothen the inter-annual variation. The distribution of the phase parameter for each future time period plotted in Fig. 4 shows that for most of the data and for each time period, the phase parameter is located between the months of June and August. To reduce the dimensionality of the sensitivity testing and thus the computational burden the phase parameter is fixed at July.

The Nash Sutcliffe Efficiency (NSE) criteria and root mean square error is used to evaluate the goodness of fit between change factors derived from the GCMs and those derived using the harmonic function. The goodness of fit plotted in Fig. 5 shows that agreement is better for later time periods as changes become more pronounced. While a large number of efficiency criteria exist (e.g. NSE, coefficient of determination, index of agreement etc.) that can be used to judge the goodness of fit, the selection of particular criteria is predominantly a subjective decision.

Table 3

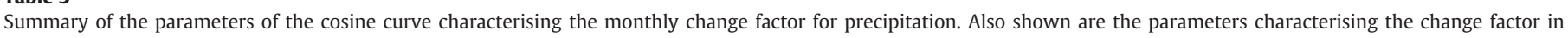

\begin{tabular}{|c|c|c|c|c|c|c|c|c|c|}
\hline \multirow[t]{3}{*}{ Sn } & \multirow[t]{3}{*}{ Scheme } & \multicolumn{4}{|c|}{$\begin{array}{l}\text { Parameter of cosine curve characterising the } \\
\text { monthly change factor for precipitation }\end{array}$} & \multicolumn{4}{|c|}{ Annual average changes in temperature } \\
\hline & & \multicolumn{2}{|l|}{ Mean } & \multicolumn{2}{|c|}{ Amplitude } & \multicolumn{2}{|l|}{ Mean } & \multicolumn{2}{|c|}{ Coeff of variation } \\
\hline & & Min & Max & Min & Max & Percentile (5) & Percentile (95) & Percentile (5) & Percentile (95) \\
\hline 1 & $2020 s$ & -0.0483 & 0.063 & 0.1 & 0.14 & 0.1648 & 1.4661 & -0.192 & 0.173 \\
\hline 2 & $2050 s$ & -0.05 & 0.0765 & 0.1 & 0.256 & 0.5357 & 1.8650 & -0.221 & 0.152 \\
\hline 3 & $2080 \mathrm{~s}$ & -0.08 & 0.0765 & 0.1 & 0.347 & 0.9502 & 2.7383 & -0.274 & 0.088 \\
\hline 4 & Sensitivity analysis & -0.125 & 0.125 & 0.001 & 0.5 & 0.1648 & 2.7383 & -0.2737 & 0.1729 \\
\hline
\end{tabular}
temperature. 


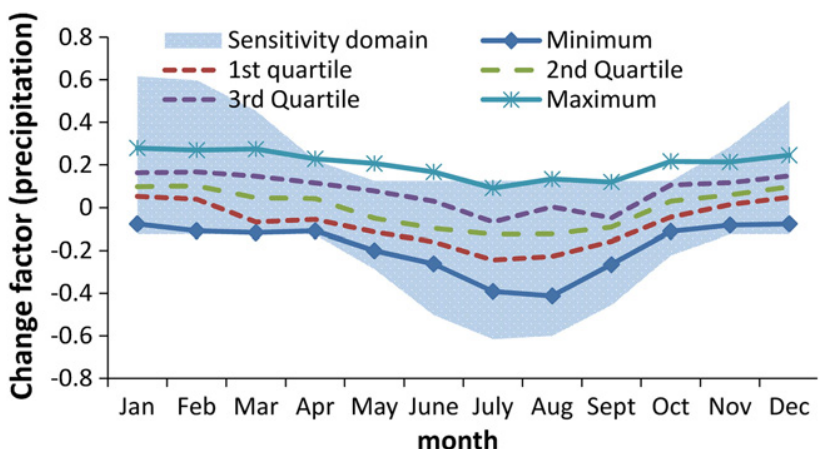

Fig. 6. Range of change factor derived from the differences in change factor estimated from different GCM and the modelled range used for the sensitivity testing.

Climate change scenarios are generated by adjusting the parameters of the WGEN weather generator based on the monthly change factors estimated from the harmonic function i.e., with mean and amplitude parameters of the cosine curve. Table 3 shows the range of the mean and amplitude parameters characterising the monthly change factor for precipitation. As highlighted above the phase parameter is fixed assuming a maximum in July. The parameter ranges used for the sensitivity analysis are 1.5 times greater than the range derived for the modelled change factor. A widened sensitivity domain is employed to include extra values at both ends of the GCM estimated range to allow for potential new extreme projections.

While the value of this approach is self-evident a potential limitation is that different GCMs may project a different seasonality of change, all being equally plausible. By approximating change factors using a harmonic function, it is quite possible that the resulting sensitivity domain for the seasonal signal may be different from that built upon the signatures derived from modelled change factors. On the other hand, building a sensitivity domain on the signature of individual GCMs would increase significantly the number of parameters and thus the complexity of the analysis. Therefore it is important that the limits of the sensitivity derived from modelled change factors encapsulate the change factors estimated from different GCMs. Fig. 6 shows the domain derived from the change factors estimated from GCMs and from the modelled change factors. For the majority of months the modelled domain encapsulates the change factor derived from the selected GCMs indicating that the range used for sensitivity testing is justifiable. However, the domain of the change factors used for the quantification of uncertainty in flood frequency for the three periods is built upon the change factor estimated from GCMs.

\subsection{Sensitivity analysis of flood peaks}

The purpose of the sensitivity analysis is to assess the effectiveness and residual risks associated with climate change allowances for peak flows in Irish river catchments, the results of which are visualised using a response surface for each catchment. The hydrological simulation involved approximately 20,000 model runs with 4 structurally different hydrological models, each with 50 behavioural parameters and 100 different daily precipitation and temperature scenarios. The temperature scenarios were subsequently used to generate an equal number of scenarios for potential evapotranspiration. Both precipitation and temperature scenarios were generated by modifying the parameters of WGEN as discussed earlier. The range of the amplitude and mean parameters of the cosine curve for precipitation and the mean and coefficient of variation parameter for temperature (shown in Table 3) were used to analyse the sensitivity of flood frequency. The analysis is based on a fully factorial experiment where the two parameters of the cosine curve are sampled at 10 discrete, equally spaced increments. The simulated time series of flow were then used to estimate 20,000 sets of annual maximum flood events, each of thirty years duration. Probability weighted moments is then used to fit the GEV distribution to each annual maximum series. Following Prudhomme et al. (2003) stationarity is assumed for each thirty year period.

Fig. 7 shows the impact of hydrological model structure and parameter uncertainty on flood quantiles for the Moy and Boyne, which represent the wettest and driest catchments respectively. For each model the results represent the uncertainty in model parameter run using a climate scenario generated from a single value of the mean and amplitude parameters. Each model displays the varying effect of parameter uncertainty on different flood quantiles. The highest uncertainty is associated with low frequency flood quantiles simulated with TANK and TOPMODEL and can be attributed to the nonlinear structure of both models. Stores are common components of all lumped rainfall-runoff models used in this study. HYMOD, NAM and TANK use the linear store i.e., the output from each is proportional to the amount of stored water. Unlike HYMOD and NAM, TANK uses two outlets to simulate surface runoff. This nonlinear structure in the surface reservoir allows TANK to represent diverse hydrograph types (see Sugawara, 1995). TOPMODEL uses an exponential store where output is exponentially related to storage. The exponential store is generally considered to be a tool for recession and base flow simulation but, as part of a rainfall runoff model, it can also play an important role in the simulation of high flow events. The differences and extent of uncertainty highlighted in Fig. 7 emphasise the importance of incorporating model structure and parameter uncertainty in estimating climate

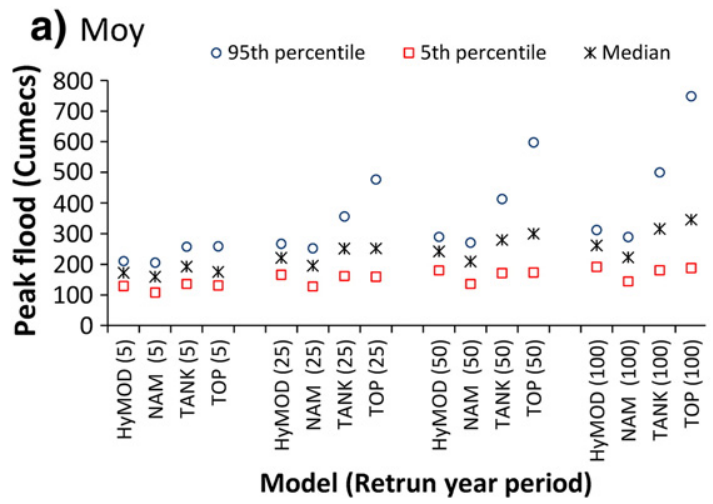

\section{b) Boyne}

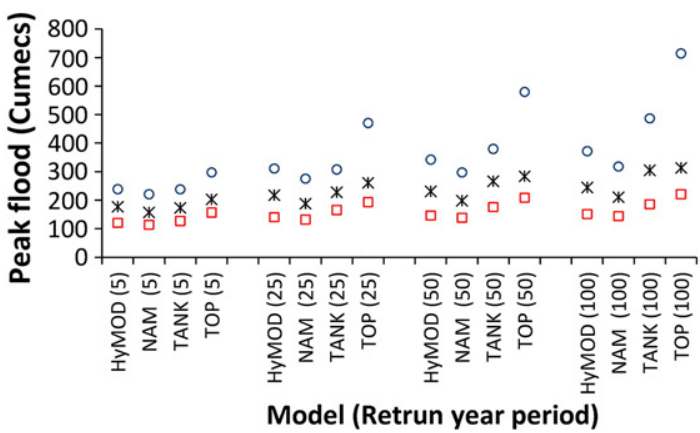

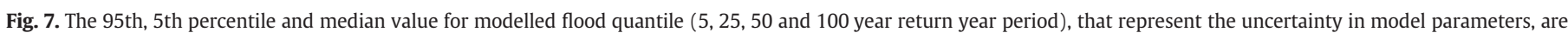
shown in (a) Moy river basin, and (b) Boyne river basin. 
a)

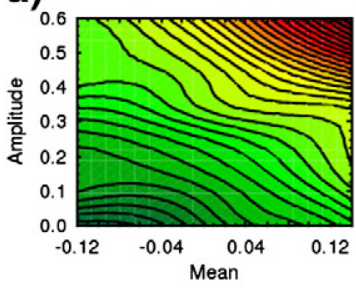

e)

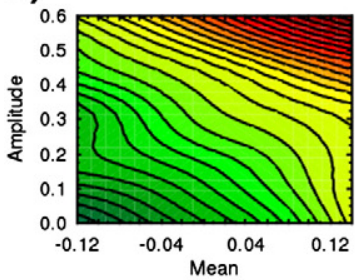

i)

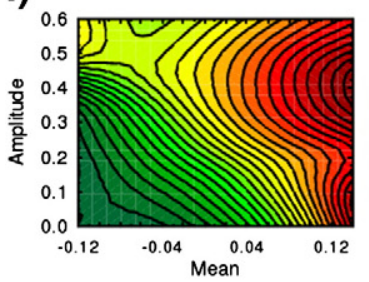

m)

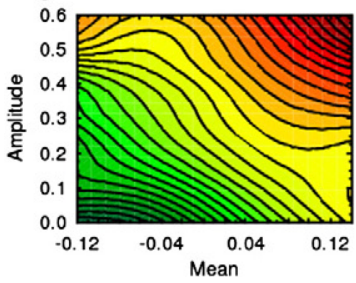

b)

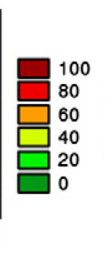

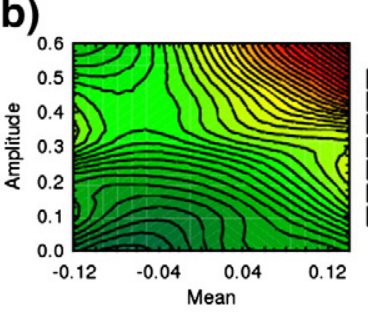

f)
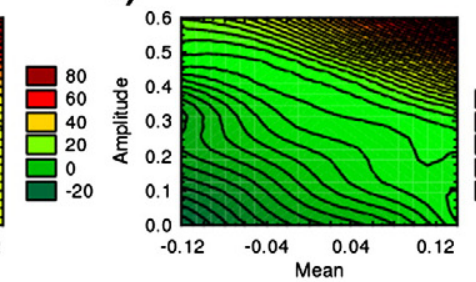

j)

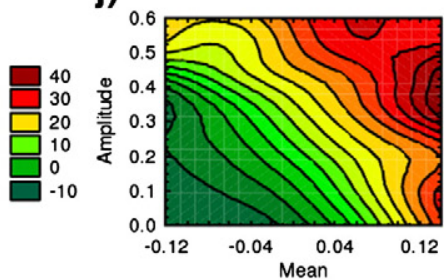

n)
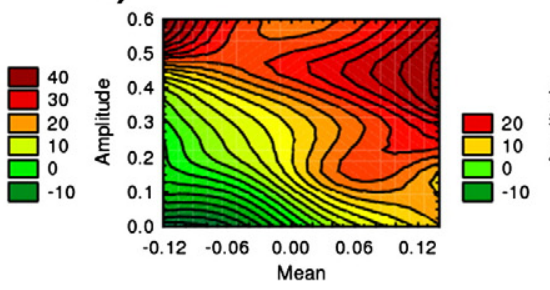

c)

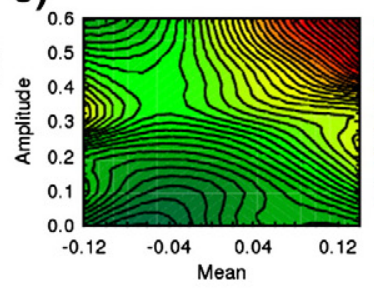

g)

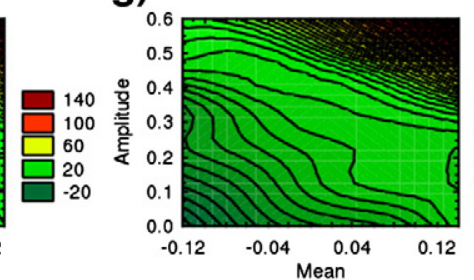

k)

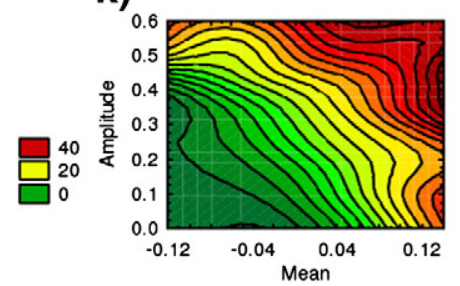

o)

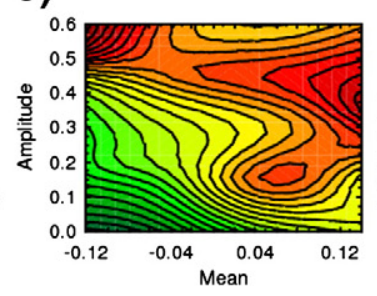

d)
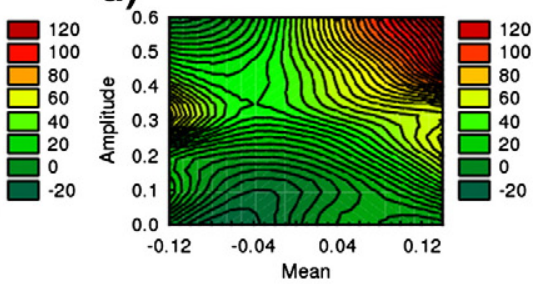

h)

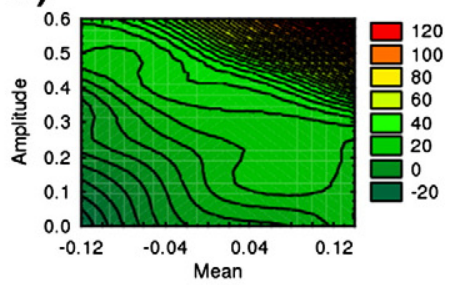

l)

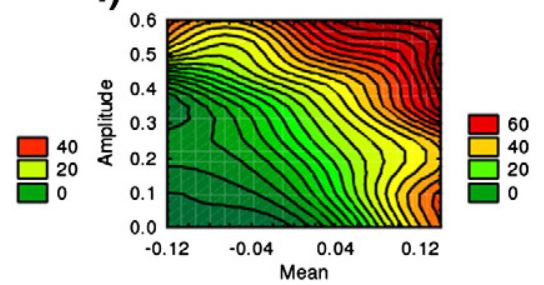

p)

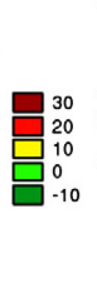

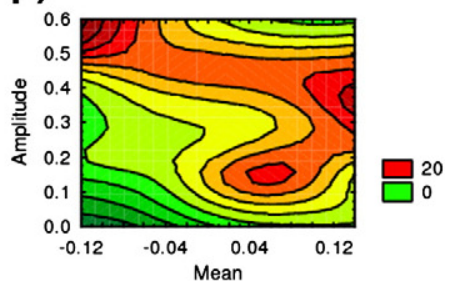

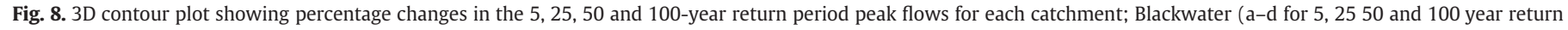

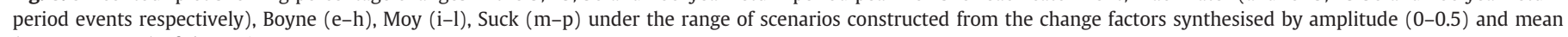
$(-0.125-0.125)$ of the cosine curve.

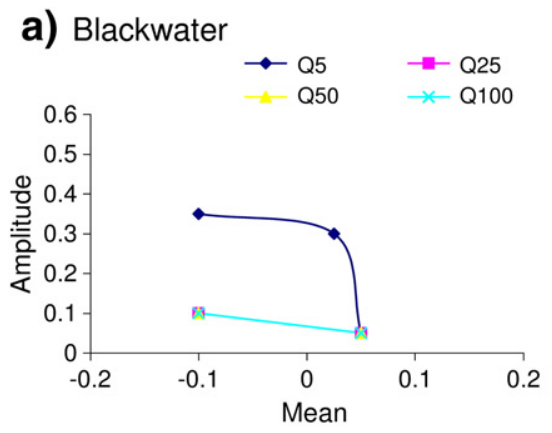

b) Boyne
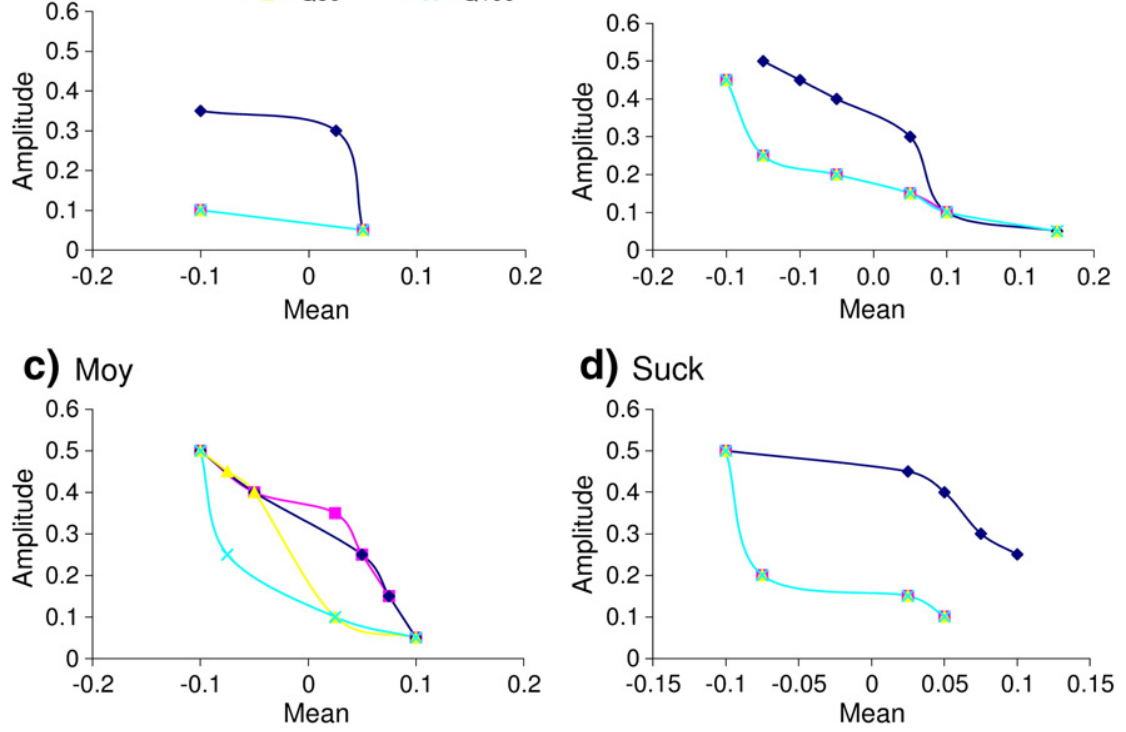

d) Suck

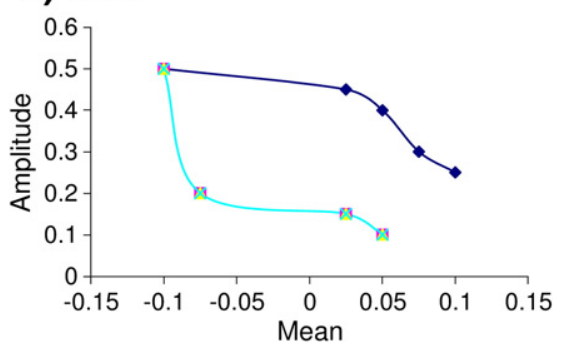

Fig. 9. Pareto front corresponding to a $+20 \%$ allowance in the peak flow associated with 5, 25, 50 and 100 -year recurrence period. 
change impacts on flood quantiles, particularly for larger extremes with lower frequencies of occurrence.

The results of the sensitivity analysis of precipitation scenarios are summarised using the 3D contour plots in Fig. 8 which show the percentage changes in the 95th percentile flow of the specified return period, estimated with respect to the 95th percentile flow of the same return period from present climatic conditions. The colours represent intervals, whereas the legend corresponds to the threshold values. The plots help in assessing the design allowances or safety margins identified for dealing with climate change. As expected, an increase in the frequency of all return periods (5, 25, 50 and 100 years) analysed is found for an increase in the mean and variability of rainfall. However, the magnitude of changes in flood frequency varied considerably for different catchments with greatest change evident for the Blackwater and Boyne, the two largest catchments analysed. The smallest changes are simulated for the Suck, the smallest catchment in the study. The plot is further summarised using the Pareto front in Fig. 9. The Pareto points separate the combination of mean and amplitude parameters of the monthly precipitation change factors that result in impacts greater or smaller than the design allowance (in this case $+20 \%$ of peak river

a)

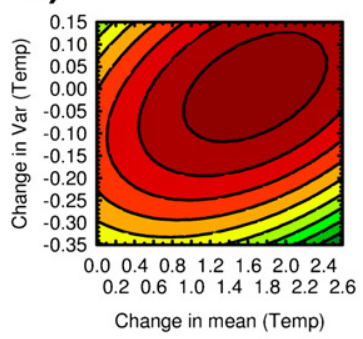

e)

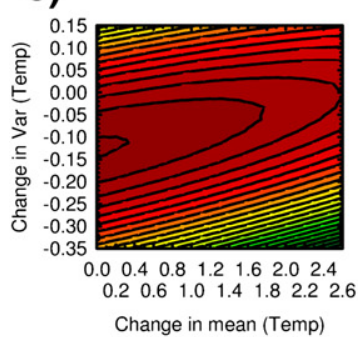

i)

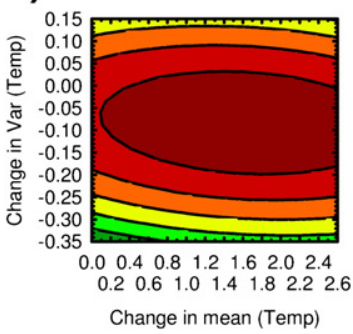

m)

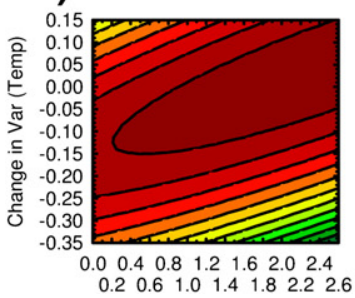

b)

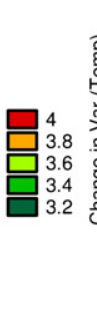

f)

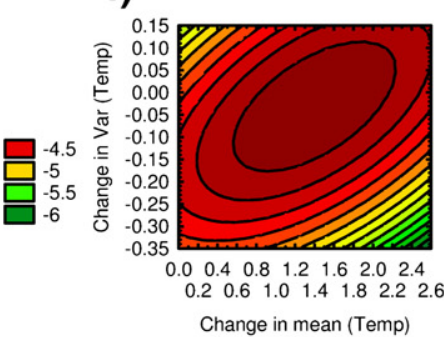

j)

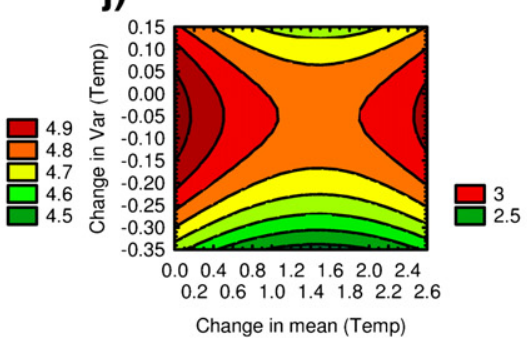

n)

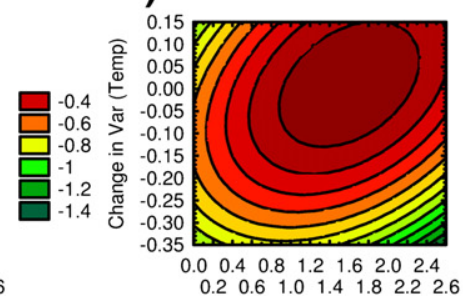

flows for the current climate). Results show that floods with a high recurrence period (e.g., 5 year return period event) lie above the low frequency events (e.g. 100 year return period event) for the Blackwater, Suck and Boyne. For these catchments, the impact of climate change is not as great for flood peaks with smaller return periods. Consequently, for low frequency events, the risk of exceedence of design allowances of $+20 \%$ of flood peak is greater, with considerable implications for critical infrastructure, e.g. culverts, bridges and flood defences whose design is normally associated with higher return period events. For, the Moy catchment the pareto front is similar for each return period analysed.

Similarly, the sensitivity of flood peaks for each return period to changes in PET, characterised as a function of the change factor in annual average maximum and minimum temperature and the coefficient of variation, is shown in Fig. 10. Compared to rainfall, the impact of temperature and consequently PET on peak flood is negligible with the sensitivity in response to PET being significantly smaller than precipitation i.e. the percentage change in flood quantile for the range of scenarios is well within $5 \%$ for all catchments except the Boyne, which has the smallest runoff coefficient of the selected catchments. The

c)

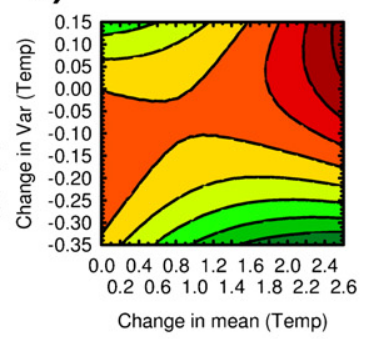

g)

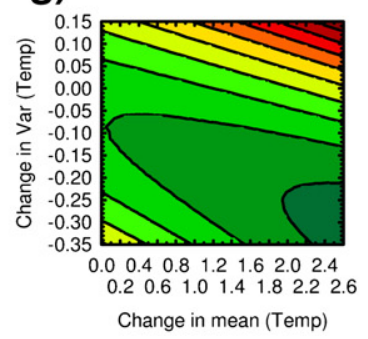

k)
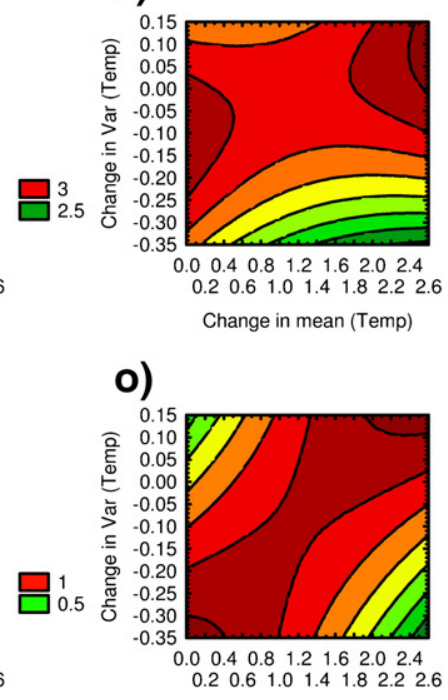

o)

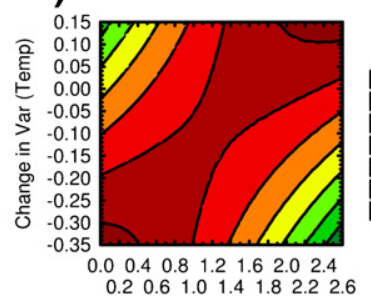

d)

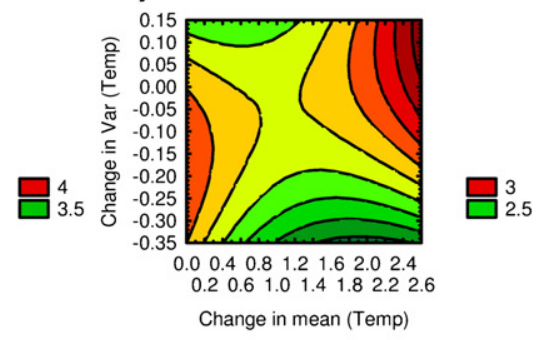

h)

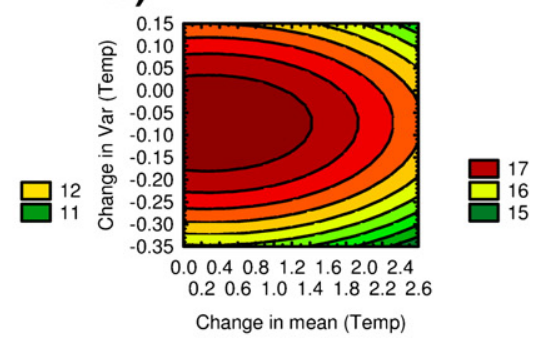

I)

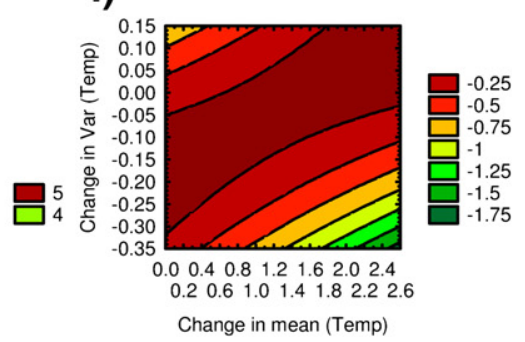

p)

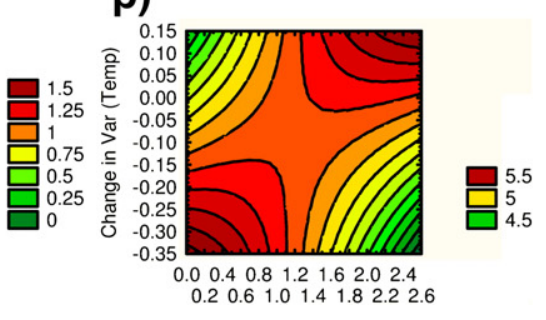

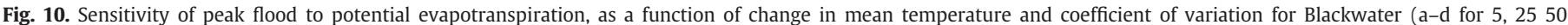

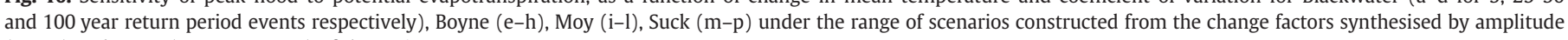
$(0-0.5)$ and mean $(-0.125-0.125)$ of the cosine curve. 
Boyne shows a slightly elevated sensitivity to mean and variability changes in temperature. Such nonlinear behaviour is common in catchments with low runoff coefficients (Nemec and Schaake, 1982).

\subsection{Future hydrologic impact}

The purpose of simulating future hydrologic impacts is to examine the associated uncertainties using the case study catchments that were used for sensitivity testing. Future impacts are calculated based on the propagation of sampled scenarios through a set of conceptual models and plausible simulators (see Fig. 2). The range of impacts in flood quantiles therefore represents the uncertainty in GCM, emission scenarios and hydrological modelling (structural and parametric sources).

The same number of simulations as discussed above was used for assessing the impact of future changes. Given the low sensitivity of flood frequency to changes in temperature and consequently PET only three sets of values representing the 1 st 2 nd and 3rd quartile derived from the range of change factors for maximum and minimum temperature were considered for the estimation of PET. The PET is estimated from temperature using Hargreaves method (see Section 2.2). Subsequently, for each of the 100 precipitation time series, the PET time series is randomly sampled with replacement from the three different sets of PET (i.e., 1st 2nd and 3rd quartile) to construct 100 pairs of PET datasets for hydrological model simulation.

Fig. 11(a) shows the width of upper 95th percentile and the lower 5th percentile flood peak associated with the 5, 25, 50 and 100 year return period events for each catchment and for each future time period. Natural climate variability is simulated using the weather generator (referred to as ClimVar). The magnitude of uncertainty arising from natural climate variability is similar to the uncertainty associated with future climate for the Boyne and Suck catchments for each future time period. However, for the Moy and Blackwater, the uncertainty associated with future impacts is marginally greater than the impact of natural variability (see Fig. 10(a)). The uncertainties in low frequency flood events, in terms of flow rate, are higher than for the high frequency events. Fig. 11(b) summarises the simulations in terms of percentage change, estimated based on the same flood quantile derived from climate scenarios generated from the unmodified weather generator (present) referred to as ClimVar, and the modified weather generator (future). Compared to more common, high frequency events, the uncertainty in changes for low frequency events is high for the Moy and Blackwater catchments and small for the Boyne and Suck. The impact of climate variability indicates that it

a)

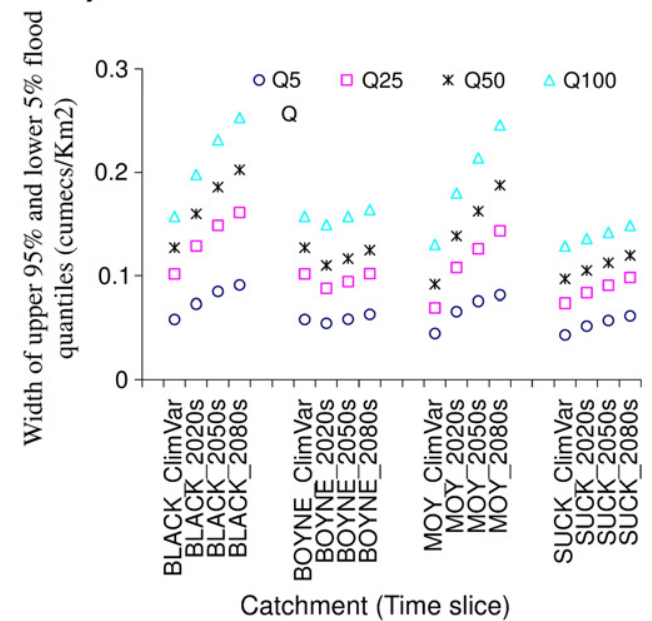

has a significant influence in all four catchments and for higher return period flow in particular.

Table 4 shows the simulation result for future time periods for the median, lower $5 \%$ and upper $95 \%$ value of flood flows for the five return periods. There is a progressive increase in the peak flow associated with the 5, 25, 50 and 100-year return periods when moving from the 2020s to the 2080s for all catchments. The percentage change however, varied among catchments. This uncertainty in flood frequency is due to the uncertainty in GCMs, scenarios and hydrological models. The average width of the uncertainty range and the size of the range for each catchment reveals that the uncertainties in low frequency events are greater than high frequency events e.g., the uncertainty in the estimation of 100 year return year flood is greater than that for the 5 year return period flow. In addition, the uncertainty interval, estimated as the average width of the uncertainty range of flow for the five return periods, grows wider with a decrease in the runoff coefficient and wetness index of each catchment, both of which tend to increase the nonlinearity in the rainfall response. The runoff coefficient for the Boyne and Suck is markedly lower than for the Blackwater and Moy.

\section{Conclusion}

Future projections of climatic change are subjected to large uncertainties. Consequently, impact assessments lead to a wide range of possible outcomes that are practically very difficult to handle. In moving from top down predict and provide approaches to climate change adaptation this study aims to build on previous work to establish best practice for stress testing important adaptation decisions. We address the major sources of uncertainty in the hydrological impacts of climate change using a multi-model approach combining output from multiple emission scenarios, GCMs and conceptual rainfall runoff models within the generalised likelihood uncertainty estimation framework, to quantify uncertainty in future impacts at the catchment scale. The paper revisits the analysis of the impact of climate change on flood frequency using a sensitivity based approach to quantify the response of the hydrological system, measured as the percentage change in flood quantile to the quantum of change. The sensitivity of the impact of climate change in the flood event of a specified return period is demonstrated through the simulation results for four Irish river catchments.

For each of the selected catchments the sensitivity analysis is used to stress test design and safety margin allowances made for climate change in critical infrastructure to uncertainties in hydrological

\section{b)}

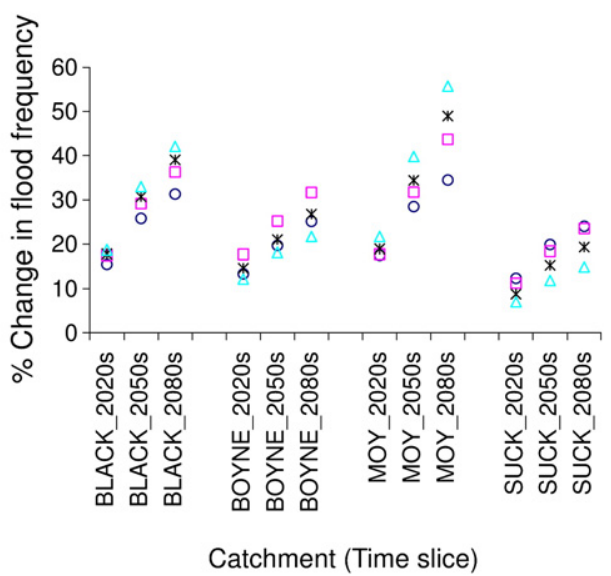

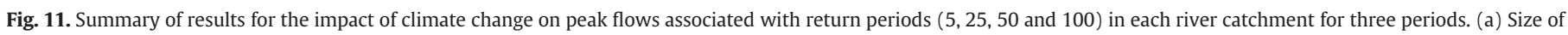
the range estimated from upper 95\% and lower 5\% flood quantiles. (b) Percentage changes in the five return year period flows. 


\section{Table 4}

Description of simulation results, median, lower $5 \%$ and upper $95 \%$ value of the flood quantiles for the three future time period. Changes are calculated based on the corresponding flood frequency curve estimated for the present climate.

\begin{tabular}{|c|c|c|c|c|c|c|c|}
\hline \multirow[t]{2}{*}{ Sno } & \multirow[t]{2}{*}{ Basin } & \multirow[t]{2}{*}{ Period } & \multirow{2}{*}{$\begin{array}{l}\text { Change from } \\
\text { (base line)/change } \\
\text { to future }\end{array}$} & \multicolumn{4}{|c|}{ Return period (year) } \\
\hline & & & & 5 & 25 & 50 & 100 \\
\hline 1 & Blackwater & $2020 s$ & Lower 5\% & 8.2 & 7.7 & 7.6 & 8.2 \\
\hline 2 & & & Median & 9.6 & 9.2 & 9.3 & 9.2 \\
\hline 3 & & & Upper 95\% & 15.5 & 17.5 & 17.8 & 18.8 \\
\hline 4 & & & $\begin{array}{l}\text { Size of range } \\
\left(\text { cumecs } / \mathrm{km}^{2}\right)\end{array}$ & 0.073 & 0.129 & 0.160 & 0.198 \\
\hline 5 & & $2050 s$ & Lower $5 \%$ & 11.1 & 10.9 & 11.0 & 11.6 \\
\hline 6 & & & Median & 14.1 & 14.0 & 14.4 & 14.9 \\
\hline 7 & & & Upper 95\% & 25.8 & 29.1 & 30.7 & 33.0 \\
\hline 8 & & & Size of range & 0.085 & 0.149 & 0.186 & 0.231 \\
\hline 9 & & $2080 s$ & Lower 5\% & 12.7 & 12.6 & 13.2 & 13.8 \\
\hline 10 & & & Median & 16.0 & 15.6 & 15.7 & 15.8 \\
\hline 11 & & & Upper 95\% & 31.3 & 36.3 & 39.1 & 42.1 \\
\hline 12 & & & $\begin{array}{l}\text { Size of range } \\
\left(\text { cumecs } / \mathrm{km}^{2} \text { ) }\right.\end{array}$ & 0.09 & 0.16 & 0.20 & 0.25 \\
\hline 13 & Boyne & $2020 s$ & Lower $5 \%$ & 4.3 & 5.5 & 5.6 & 5.9 \\
\hline 14 & & & Median & 8.5 & 9.1 & 9.4 & 10.4 \\
\hline 15 & & & Upper 95\% & 13.4 & 17.7 & 14.6 & 12.2 \\
\hline 16 & & & $\begin{array}{l}\text { Size of range } \\
\text { (cumecs } / \mathrm{km}^{2} \text { ) }\end{array}$ & 0.055 & 0.088 & 0.110 & 0.149 \\
\hline 17 & & $2050 s$ & Lower $5 \%$ & 7.9 & 10.1 & 10.7 & 11.6 \\
\hline 18 & & & Median & 12.8 & 13.3 & 13.6 & 14.8 \\
\hline 19 & & & Upper 95\% & 19.7 & 25.2 & 21.0 & 18.2 \\
\hline 20 & & & $\begin{array}{l}\text { Size of range } \\
\left(\text { cumecs } / \mathrm{km}^{2} \text { ) }\right.\end{array}$ & 0.059 & 0.094 & 0.117 & 0.157 \\
\hline 21 & & $2080 s$ & Lower $5 \%$ & 8.0 & 10.3 & 10.8 & 11.3 \\
\hline 22 & & & Median & 14.5 & 15.3 & 15.6 & 16.8 \\
\hline 23 & & & Upper 95\% & 25.1 & 31.7 & 26.8 & 21.7 \\
\hline 24 & & & $\begin{array}{l}\text { Size of range } \\
\left(\text { cumecs } / \mathrm{km}^{2} \text { ) }\right.\end{array}$ & 0.063 & 0.102 & 0.125 & 0.164 \\
\hline 25 & Moy & $2020 s$ & Lower $5 \%$ & 10.8 & 10.2 & 10.0 & 9.6 \\
\hline 26 & & & Median & 11.5 & 11.4 & 11.3 & 11.1 \\
\hline 27 & & & Upper 95\% & 17.5 & 17.8 & 18.9 & 21.7 \\
\hline 28 & & & $\begin{array}{l}\text { Size of range } \\
\text { (cumecs } / \mathrm{km}^{2} \text { ) }\end{array}$ & 0.066 & 0.108 & 0.139 & 0.180 \\
\hline 29 & & $2050 s$ & Lower $5 \%$ & 14.3 & 14.7 & 15.0 & 14.8 \\
\hline 30 & & & Median & 17.5 & 18.0 & 18.5 & 18.6 \\
\hline 31 & & & Upper 95\% & 28.5 & 31.7 & 34.4 & 39.8 \\
\hline 32 & & & $\begin{array}{l}\text { Size of range } \\
\left(\text { cumecs } / \mathrm{km}^{2} \text { ) }\right.\end{array}$ & 0.08 & 0.13 & 0.16 & 0.21 \\
\hline 33 & & $2080 s$ & Lower $5 \%$ & 15.0 & 15.5 & 15.8 & 16.5 \\
\hline 34 & & & Median & 19.6 & 21.0 & 21.9 & 22.5 \\
\hline 35 & & & Upper 95\% & 34.5 & 43.7 & 49.0 & 55.7 \\
\hline 36 & & & $\begin{array}{l}\text { Size of range } \\
\left(\text { cumecs } / \mathrm{km}^{2} \text { ) }\right.\end{array}$ & 0.082 & 0.143 & 0.188 & 0.246 \\
\hline 37 & Suck & $2020 s$ & Lower $5 \%$ & 6.8 & 8.6 & 9.3 & 9.5 \\
\hline 38 & & & Median & 9.5 & 9.9 & 10.0 & 10.0 \\
\hline 39 & & & Upper 95\% & 12.4 & 11.3 & 8.8 & 7.0 \\
\hline 40 & & & $\begin{array}{l}\text { Size of range } \\
\left(\text { cumecs } / \mathrm{km}^{2} \text { ) }\right.\end{array}$ & 0.052 & 0.084 & 0.105 & 0.136 \\
\hline 41 & & $2050 s$ & Lower 5\% & 10.5 & 13.1 & 14.2 & 14.8 \\
\hline 42 & & & Median & 14.7 & 15.5 & 16.2 & 16.4 \\
\hline 43 & & & Upper 95\% & 19.9 & 18.4 & 15.3 & 11.9 \\
\hline 44 & & & $\begin{array}{l}\text { Size of range } \\
\text { (cumecs } / \mathrm{km}^{2} \text { ) }\end{array}$ & 0.057 & 0.091 & 0.113 & 0.142 \\
\hline 45 & & $2080 s$ & Lower $5 \%$ & 10.0 & 12.3 & 13.3 & 14.0 \\
\hline 46 & & & Median & 16.0 & 17.3 & 18.2 & 18.4 \\
\hline 47 & & & Upper 95\% & 24.0 & 23.5 & 19.3 & 14.9 \\
\hline 48 & & & $\begin{array}{l}\text { Size of range } \\
\text { (cumecs } / \mathrm{km}^{2} \text { ) }\end{array}$ & 0.062 & 0.098 & 0.120 & 0.149 \\
\hline
\end{tabular}

response. The response surfaces constructed enable the visualisation of the vulnerability of the impact system. Results show that there is a considerable residual risk associated with allowances of $+20 \%$ when uncertainties are accounted for and that the risk of exceedence of design allowances is greatest for more extreme, low frequency events with considerable implication for critical infrastructure, e.g., culverts, bridges, flood defences whose designs are normally associated with such return period events.
In terms of hydrological models, the differences and extent of uncertainty emphasise the importance of incorporating model structure and parameter uncertainty in estimating climate change impacts on flood quantiles, particularly for larger extremes with lower frequencies of occurrence. Each of the models used here displays the varying effect of parameter uncertainty on different flood quantiles. The highest uncertainty is associated with low frequency flood quantiles and with models that use nonlinear surface storage structures.

The magnitude of changes in flood frequency varied considerably for different catchments with greatest change evident for the Blackwater and Boyne, the two largest catchments analysed. The uncertainty in flood quantiles arising from natural variability was comparable to the simulated future climate change impact for the Boyne and Suck. The impact of climate variability was less than the climate change impact simulated with future scenarios for the Moy and Blackwater rivers.

In quantifying future flood behaviour the average width of the uncertainty range and the size of the range for projections is higher for low frequency events than for high frequency events, while a progressive increase in the 5, 25, 50 and 100-year return period flood is observed when moving from the 2020s to the 2080s in all catchments. The percentage change however is different among the basins selected. Results show that the impact of climate change is not as great for flood peaks with smaller return periods. Consequently, for low frequency events, the risk of exceedence of design allowances is greater with considerable implications for critical infrastructure.

Owing to simplicity and ease of application, simple change factor methods used in conjunction with a weather generator offer a useful approach for generating climate scenarios from a large range of GCMs. The use of regional climate models, which are based on physical laws, may provide better characterisation of daily scenarios and increased precision of individual scenarios for use in hydrological simulation compared to change factor method used in this study. However, this is a resource intensive task, and limits the number of GCMs that can be sampled to explore the range of uncertainty in future impacts. Furthermore, due to the differences in the sensitivity of rainfall and temperature on responsiveness of a catchment, they both were treated independent. Though the flood frequency analysis analysed in this study recognised the fact that frequency distributions are not stationary, the uncertainty associated with the fitting of the annual maximum series to generalised extreme valued distribution is not explored. Furthermore, it should also be noted that for the frequency analysis, a 30 year period is used to generate 100 year return period event. Therefore, results based on such extrapolation should be taken with caution.

\section{Acknowledgement}

This work received financial support from Science Foundation Ireland's Research Frontiers Programme under the project title 'Quantifying the cascade of uncertainty in climate change impacts for the water sector'. The quality of this paper has been greatly improved by the thoughtful comments and suggestion from two anonymous reviewers and editor assigned to handle this manuscript.

\section{References}

Ahilan S, O'Sullivan JJ, Bruen M. Influences on flood frequency distributions in Irish river catchments. Hydrol Earth Syst Sci Discuss 2011;8:3305-51.

Arnell NW, Reynard NS. The effects of climate change due to global warming on river flows in Great Britain. J Hydrol 1996;183:397-424.

Bae DH, Jung IW, Lettenmaier DP. Hydrologic uncertainties of climate change on IPCC AR4 GCM simulations in the Chungju basin, Korea. J Hydrol 2011;401(1-2): 90-105. doi:10.1016/j.jhydrol.2011.02.012.

Bastola S, Murphy C, Sweeney J. The role of hydrological modelling uncertainties in climate change impact assessments of Irish river catchments. Adv Water Resour 2011;34(5):562-76. doi:10.1016/j.advwatres.2011.01.008. 
Bastola S, Murphy C, Fealy R. Generating probabilistic estimates of hydrological response using a weather generator and probabilistic climate change scenarios. Hydrol Process under review.

Beven K, Binley AM. The future of distributed models: model calibration and uncertainty prediction. Hydrol Process 1992;6:279-98.

Beven K, Lamb R, Quinn P, Romanowicz R, Freer J. TOPMODEL. In: Singh VP, editor. Computer models of watershed hydrology. Highlands Ranch: Water Resource Publication; 1995. p. 627-68.

Cameron D. An application of the UKCIP02 climate change scenarios to flood estimation by continuous simulation for a gauged catchment in the northeast of Scotland, UK (with uncertainty). J Hydrol 2006;328:212-26.

Cameron D, Beven K, Naden P. Flood frequency estimation under climate change (with uncertainty). Hydrol Earth Syst Sci 2000;4(3):393-405.

Fatichi S, Ivanov VY, Caporali E. Simulation of future climate scenarios with a weather generator. Adv Water Resour 2011;34(4):448-67. doi:10.1016/j.advwatres.2010.12.013.

Freer J, Beven K, Ambroise B. Bayesian uncertainty in runoff prediction and the value of data: an application of the GLUE approach. Water Resour Res 1996;32(7):2161-73.

Giorgi F, Mearn L. Probability of regional climate change calculated using the reliability ensemble average (REA) method. Geophys Res Lett 2003;30:1629-32. doi: 10.1029/2003GL017130.

Hall J, Murphy C. Vulnerability analysis of future public water supply under changing climate conditions: a study of the Moy catchment, western Ireland. Water Resour Manage 2010;24(13):3527-45.

Hallegatte S. Strategies to adapt to an uncertain climate change. Glob Environ Change 2009;19:240-7.

Hargreaves GL, Hargreaves GH, Riley JP. Irrigation water requirement for Senegal River Basin. J Irrig Drain Eng ASCE 1985;111(3):265-75.

Hosking JRM. L-moments: analysis and estimation of distributions using linear combinations of order statistics. J R Stat Soc 1990;52(2):105-24

Hosking JRM, Wallis JR, Wood EF. Estimation of the generalized extreme value distribution by the method of probability weighted moments. Technometrics 1985;27(3):251-61.

Institute of Hydrology. 1999 Institute of Hydrology. Flood estimation handbook Wallingford: Institute of Hydrology; 1999.

Kay AL, Reynard NS, Jones RG. RCM rainfall for UK flood frequency estimation. I. Method and validation. J Hydrol 2006;318(1-4):151-62. doi:10.1016/j.jhydrol.2005.06.012.

Kendon EJ, Rowell DP, Jones RG, Buonomo E. Robustness of future changes in local precipitation extremes. J Climate 2008;21:4280-97.

Kilsby CG, Jones PD, Burton A, Ford AC, Fowler HJ, Harpham C, et al. A daily weather generator for use in climate change studies. Environ Modell Softw 2007;22(12):1705-19.

Kirkyla KI, Hameed S. Harmonic analysis of the seasonal cycle in precipitation over the United States: a comparison between observations and a general circulation model. J Climate 1989;12:1463-75.

Kumar R, Chatterjee C. Regional flood frequency analysis using L-moments for North Brahmaputra region of India. J Hydrol Eng 2005;10(1):1-7. doi:10.1061/(ASCE)1084-0699 (2005)10:1(1).

Lehner B, Döll P, Alcamo J, Henrichs T, Kaspar F. Estimating the impact of global change on flood and drought risks in Europe: a continental integrated analysis. Clim Change 2006;75:273-99.

Lopez A, Fung F, New M, Watts G, Watson A, Wilby RL. From climate model ensembles to climate change impacts and adaptation: a case study of water resource management in the southwest of England. Water Resour Res 2009;45:W08419.
Madsen $\mathrm{H}$. Automatic calibration of a conceptual rainfall-runoff model using multiple objectives. J Hydrol 2000;235:276-88.

Madsen H, Rasmussen PF, Rosbjerg D. Comparison of annual maximum series and partial duration series methods for modeling extreme hydrologic events. 1. At-site modelling. Water Resour Res 1997;33(4):747-57.

Murphy C, Charlton R. Climate change and water resources in Ireland. In: Sweeney J, editor. Climate change: refining the impacts. Ireland: Environmental Protection Agency, Government Publications; 2008. p. 39-81.

Nemec J, Schaake J. Sensitivity of water resource systems to climate variation. Hydrol Sci J 1982;27(3):327-43.

OPW. Assessment of potential future scenarios for flood risk management. 14 August. http://www.opw.ie/en/FloodRiskManagement/TechnicalInformation/ OperationalGuidance/ClimateChange/2009. 10 March, 2011.

Prudhomme C, Reynard N, Crooks S. Downscaling of global climate models for flood frequency analysis: where are we now? Hydrol Process 2002;16:1137-50.

Prudhomme C, Jakob D, Svensson C. Uncertainty and climate change impact on the flood regime of small UK catchments. J Hydrol 2003;277(1-2):1-23.

Prudhomme C, Wilby RL, Crooks S, Kay AL, Reynard NS. Scenario neutral approach to climate change impact studies: application to flood risk. J Hydrol 2010;390: 198-209.

Ra ïsänen J, Palmer TN. A probability and decision-model analysis of a multimodel ensemble of climate change simulations. J Climate 2001;14:3212-26.

Richarsdon CW, Wright DA. WGEN: a model for generating daily weather variables. U.S. Dep. of Agric. Agricultural Research Service ARS-8; 1984.83 pp.

Rowell DP. A demonstration of the uncertainty in projections of UK climate change resulting from regional model formulation. Clim Change 2006;79:243-57.

Schreider SY, Smith DI, Jakeman AJ. Climate change impacts on urban flooding. Clim Change 2000;47:91-115.

Sugawara M. Tank model. In: Singh VP, editor. Computer models of watershed hydrology. Littleton, Co.: Water Resources Publication; 1995. p. 165-214.

Supit I. Global radiation. Luxembourg: Publication EUR 15745 EN of the Office for Official Publications of the EU; 1994

Taye MT, Ntegeka V, Ogiramoi NP, Willems P. Assessment of climate change impact on hydrological extremes in two source regions of the Nile River Basin. Hydrol Earth Syst Sci Discuss 2010;7:5441-65.

Tung C. Climate change impacts on water resources of the Tsengwen Creek watershed in Taiwan. J Am Water Resour Assoc 2001;37(1):167-76.

Wagener T, Boyle DP, Lees MJ, Wheater HS, Gupta HV, Sorooshian S. A framework for development and application of hydrological models. Hydrol Earth Syst Sci 2001:5(1):13-26

Wilby RL, Dessai S. Robust adaptation to climate change. Weather 2010;65:180-5.

Wilby RL, Beven K, Reynard NS. Climate change and fluvial flood risk in the UK: more of the same? Hydrol Process 2008;22:2511-23.

Wilks DS. Adapting stochastic weather generation algorithms for climate changes studies. Clim Change 1992;22:67-84.

Xu CY. Climate change and hydrologic models: a review of existing gaps and recent research developments. Water Resour Manage 1999;13:369-82.

$\mathrm{Xu}$ CY, Singh VP. Evaluation and generalization of radiation based methods for calculating evaporation. Hydrol Process 2000;14:339-49. 